Grand Valley State University

ScholarWorks@GVSU

\title{
Preference and Perceived Danger as a Function of the Perceived Curvature, Length, and Width of Urban Alleys
}

Thomas R. Herzog

Grand Valley State University, herzogt@gvsu.edu

Jennifer A. Flynn-Smith

Grand Valley State University

Follow this and additional works at: https://scholarworks.gvsu.edu/psy_articles

Part of the Psychology Commons

\section{ScholarWorks Citation}

Herzog, Thomas R. and Flynn-Smith, Jennifer A., "Preference and Perceived Danger as a Function of the Perceived Curvature, Length, and Width of Urban Alleys" (2001). Peer Reviewed Articles. 21.

https://scholarworks.gvsu.edu/psy_articles/21

This Article is brought to you for free and open access by the Psychology Department at ScholarWorks@GVSU. It has been accepted for inclusion in Peer Reviewed Articles by an authorized administrator of ScholarWorks@GVSU.

For more information, please contact scholarworks@gvsu.edu. 


\section{PREFERENCE AND PERCEIVED DANGER AS A FUNCTION OF THE PERCEIVED CURVATURE, LENGTH, AND WIDTH OF URBAN ALLEYS}

THOMAS R. HERZOG is a professor of psychology at Grand Valley State University in Allendale, Michigan. His current research focuses on environmental preferences, restorative environments, and the psychology of humor.

JENNIFER A. FLYNN-SMITH received her bachelors degree in psychology from Grand Valley State University.

ABSTRACT: Herzog and Miller (1998) reported that people judged alleys with sharper curves as less dangerous than straighter alleys. The authors investigated the role of perceived alley length as a possible confounding influence. Raters judged a large sample of urban alleys for two target variables (preference and danger) and six predictor variables (setting care, mystery, shadow, curvature, length, and width). The partial correlation of danger and curvature, with length partialed out, was not significant. However, in regression analyses controlling for the entire set of predictors, curvature had a modest negative partial relation with preference and a tendency toward a modest positive partial relation with danger. Thus, when controlling for all predictors, the counterintuitive relation between danger and curvature disappears. In the regression analyses, the strongest predictors were setting care (positive for preference, negative for danger) and shadow (the opposite pattern). Mystery tended to be positively related to both target variables.

The field of environmental criminology deals with the relation between crime and the environment (Brantingham \& Brantingham, 1993). One focus of psychological research in this area has been the identification of environmental features that contribute to the fear of crime. An ironic finding from

AUTHORS' NOTE: Correspondence concerning this article should be addressed to Thomas R. Herzog, Department of Psychology, Grand Valley State University, Allendale, Michigan 49401; e-mail: herzogt@gvsu.edu.

ENVIRONMENT AND BEHAVIOR, Vol. 33 No. 5, September 2001 653-666 () 2001 Sage Publications 
this body of research is that many of the same features that have been found to be positive predictors of preference in natural settings are also positive predictors of fear of crime in urban settings (e.g., Fisher \& Nasar, 1992; Loewen, Steel, \& Suedfeld, 1993; Nasar \& Fisher, 1993; Nasar \& Jones, 1997). Such features include mystery (the promise of further information if one could penetrate more deeply into a setting), vegetation, shadow, and other features that afford concealment. For example, in the study by Nasar and Jones, college women walked a campus route after dark and reported their feelings into a recorder. Content analysis of the comments revealed that environmental features affording concealment, such as shrubs and bushes, were a major contributor to fear reactions.

As far as urban nature is concerned, a counterattack has been launched recently in a series of studies documenting the beneficial effects of nature in the urban setting (e.g., Kuo, 2001; Kuo, Bacaicoa, \& Sullivan, 1998; Wells, 2000). For example, in the study by Kuo et al., residents of a public-housing project rated photos of their neighborhood for preference and sense of safety. The photos systematically varied levels of tree density, tree placement, and grass maintenance. The most surprising result was that as tree density increased, both preference and sense of safety also increased. Similarly, Wells, using a longitudinal design, compared levels of cognitive functioning for low-income children who relocated to settings varying in nature content. She found that those who relocated to more natural settings had higher levels of cognitive functioning following the move, as reported by their mothers using a standardized rating scale. In the same vein, Kuo compared publichousing residents who had been randomly assigned to buildings with and without nearby nature. Those in the latter group reported more procrastination in dealing with major life issues and assessed such issues as more severe, less soluble, and more longstanding than did those living in the more natural settings.

A balanced view of the controversy is that many environmental features in urban settings can promote either preference or fear reactions depending on the context in which they appear. Context includes the physical arrangement of features (e.g., limbed-up trees versus ground shrubs that could be used as hiding places), cues to setting care (the "broken-windows" hypothesis), knowledge about the setting (including reputations as dangerous or safe places), and biases attributable to cultural, ethnic, or even personality factors. This balanced view is discussed, at least in part, in several sources (Herzog \& Miller, 1998; Kuo et al., 1998; Nasar \& Jones, 1997).

The point of departure for the research reported here was a curious finding of Herzog and Miller (1998). They assessed preference and perceived danger (which they interpreted as a fear reaction) for urban alleys and field-forest 
settings, all of which contained visible pathways. They also measured the perceived curvature of the pathways and two other predictors: mystery and openness. The curious finding was an interaction of setting category and perceived curvature in predicting perceived danger. Curvature was a negative predictor of perceived danger for the alleys and was not an effective predictor for the field-forest settings. The finding showed up in both the simple correlations and in model testing that took into account the other predictor variables. The finding implied that the straight alleys were seen as more dangerous than the curved ones. This result was counterintuitive because the researchers had expected that the curved alleys would be seen as more dangerous inasmuch as they afford concealment for urban predators. The authors suggested post hoc that the straight alleys seemed longer perceptually and perhaps for that reason were seen as more forbidding. They suggested disentangling curvature and length in future research.

The study reported here follows up on their suggestion. A larger sample of urban alleys was used ( 18 in their study, 60 in this study). The dependent variables were rated preference and perceived danger. In selecting settings for this study, a conscious attempt was made to include a wide range of pathway curvature and perceived length and all combinations of the two predictors. A wide range of alley widths was also included so that the effect of width as a predictor, in combination with curvature and length, could be assessed. The rated predictors included perceived pathway curvature, length, and width, as well as mystery, setting care, and shadow. Mystery was shown to be a positive predictor of both preference and danger in the Herzog and Miller (1998) study even though preference and danger were negatively related to each other. Setting care taps into the broken-windows hypothesis and thus draws support from the wide range of studies implicating maintenance as a predictor of fear of crime (e.g., Perkins, Meeks, \& Taylor, 1992; Perkins, Wandersman, Rich, \& Taylor, 1993; Schroeder \& Anderson, 1984; Taylor, Shumaker, \& Gottfredson, 1985; Wilson, 1975; Wilson \& Knelling, 1982). As a rated predictor, setting care was shown to have a negative relation to perceived danger for urban settings by Herzog and Chernick (2000). The prevalence of shadows in an urban alley might be expected to be a positive predictor of perceived danger, although the ability of shadow to predict independently of mystery remains to be seen. A close relative of shadow, lighting level, has empirical support as a predictor of perceived danger in urban settings (Loewen et al., 1993). A final question addressed by this study was whether preference reactions in a stereotypically dangerous setting (urban alleys) are affected by guarantees of safety. To find out, we compared results for preference defined without reference to safety and preference defined with the proviso that safety in the setting was absolutely guaranteed. 


\section{METHOD}

\section{PARTICIPANTS}

The sample consisted of 395 undergraduate students (130 men, 264 women, and 1 respondent who failed to report gender) at a university in the Midwestern United States. The students participated to fulfill a course requirement in introductory psychology. Twenty-four sessions consisting of between 6 and 26 participants were run.

\section{STIMULI}

The settings consisted of 60 color slides of urban alleys. They were selected from an extensive collection of research slides by the first author to span a broad range of values on the predictor variables described below. There was also a conscious attempt to include all combinations of high and low values of the predictor variables pathway curvature and alley length. Figures 1 through 3 contain some examples illustrating the various combinations of these variables. None of the settings contained people. All settings were photographed in summer or early fall, and extreme weather conditions were avoided. All slides were oriented horizontally.

\section{PROCEDURE}

Participants in each session rated each of the 60 settings on only one of the variables described here, with all participants in a session rating the same variable. All ratings used a 5-point scale ranging from A (very high) to $\mathrm{E}$ (not at all). The letters A through $\mathrm{E}$ were later converted to the numbers 5 through 1 , respectively, for analysis. There were two versions of the target variable preference. The first, referred to here as preference, was defined as "How much do you like the setting? This is your own personal degree of liking for the setting, and you don't have to worry about whether you're right or wrong or whether you agree with anybody else." The second version of preference, referred to here as preference (safety guaranteed), used exactly the same definition, but it was preceded by the phrase "Assuming that your safety is absolutely guaranteed and that there is no chance that you could be harmed in this setting." The target variable danger was defined as "How dangerous is this setting? How likely is it that you could be harmed in this setting?" There were six rated predictor variables. Setting care was defined as "How well cared-for does the setting seem to be? Is it in good condition and well maintained?" Mystery was defined as "How much does the setting promise more to be seen 

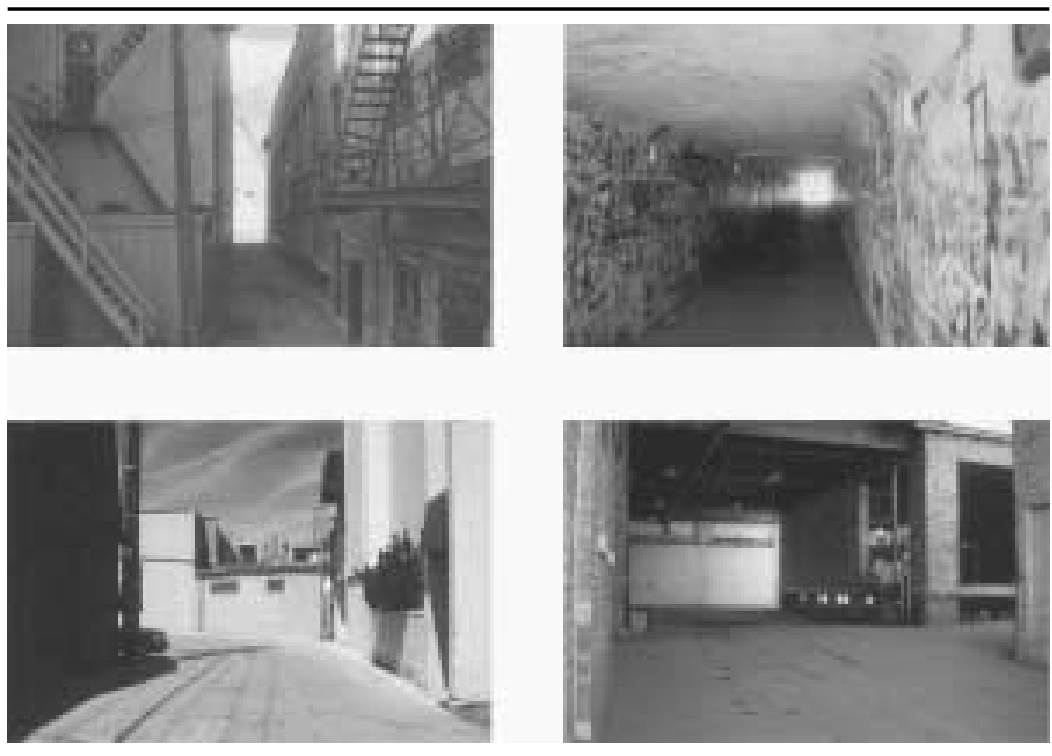

Figure 1: Alleys Low (Top Row) and High (Bottom Row) in Curvature

Mean Ratings for Curvature (C), Length (L), and Width (W): $C=1.13, L=4.22, W=1.91$ (Top Left); $\mathrm{C}=1.13, \mathrm{~L}=4.50, \mathrm{~W}=2.67$ (Top Right); $\mathrm{C}=4.42, \mathrm{~L}=2.75, \mathrm{~W}=4.09$ (Bottom Left); $\mathrm{C}=4.39, \mathrm{~L}=2.47$, $\mathrm{W}=4.06$ (Bottom Right).

if you could walk deeper into it? Does the setting seem to invite you to enter more deeply into it and thereby learn more?" Shadow was defined as "How much are shadows important or dominant in the setting?" Curvature was defined as "Consider how much the alley curves or bends. The strongest curvature you will see will be about 90 degrees or a right-angle bend. Such alleys should be rated high (A) in Curvature. If the alley is completely straight, with no curvature at all, rate it low (E) in Curvature." Width was defined as "How wide does the alley appear to be from its left-hand border or side to its righthand border or side?" Length was defined as "How long does the alley appear to be from its nearest to its farthest visible point?"

Sessions proceeded as follows. First, five practice slides were presented to help participants get used to the task and their instructions for responding. Then participants rated 64 slides, presented in two sets of 32 slides each with a 2-minute rest between sets. The first and last slide within each set were fillers, intended to absorb any beginning- or end-of-set effects. The remaining 60 slides yielded the data for analysis. These slides were presented in one of two orders. The first order was used for the first 12 sessions, the second order for the last 12 sessions. Within each block of sessions using a given slide 


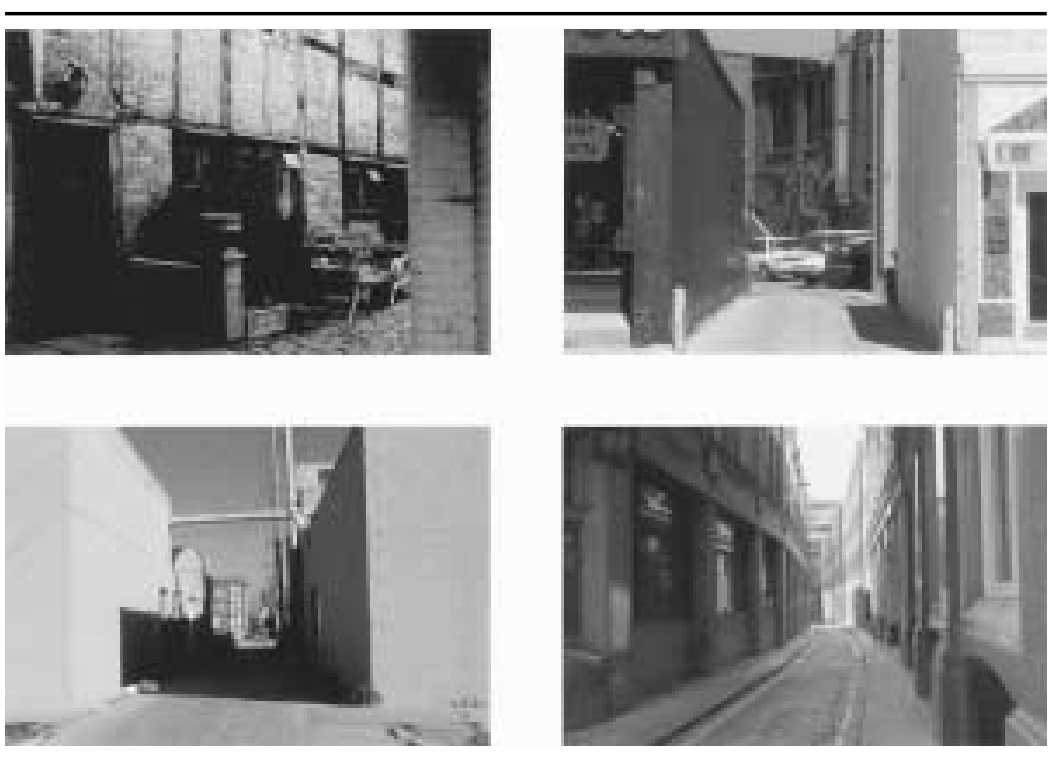

Figure 2: Alleys Low (Top Row) and High (Bottom Row) in Length

Mean Ratings for Curvature (C), Length ( $L$ ), and Width (W): $C=3.81, L=1.50, W=2.58$ (Top Left); $C=3.39, L=1.78, L=2.97$ (Top Right); $C=1.74, L=4.69, W=3.58$ (Bottom Left) $C=2.74, L=4.59$, $\mathrm{W}=2.73$ (Bottom Right).

order, there were four sessions devoted to preference and one session devoted to each of the other eight rated variables. The extra sessions for preference afforded us the option of factor analyzing the preference ratings (see Note 1). Aside from the constraints on the ordering of sessions just noted, the ordering of sessions was haphazard. One of the slide presentation orders was generated randomly, and the second presentation order was derived by interchanging the halves of the first order. Viewing time was 15 seconds per slide in all sessions. Final sample sizes were 135 for preference, 36 for mystery, 34 for shadow, 33 for danger and width, 32 for setting care and length, 31 for curvature, and 29 for preference (safety guaranteed).

\section{RESULTS}

All analyses were based on setting as the unit of analysis and setting scores as raw scores. A setting score is the mean score for each setting based on all participants who completed one of the rating tasks. Thus, for each rated 

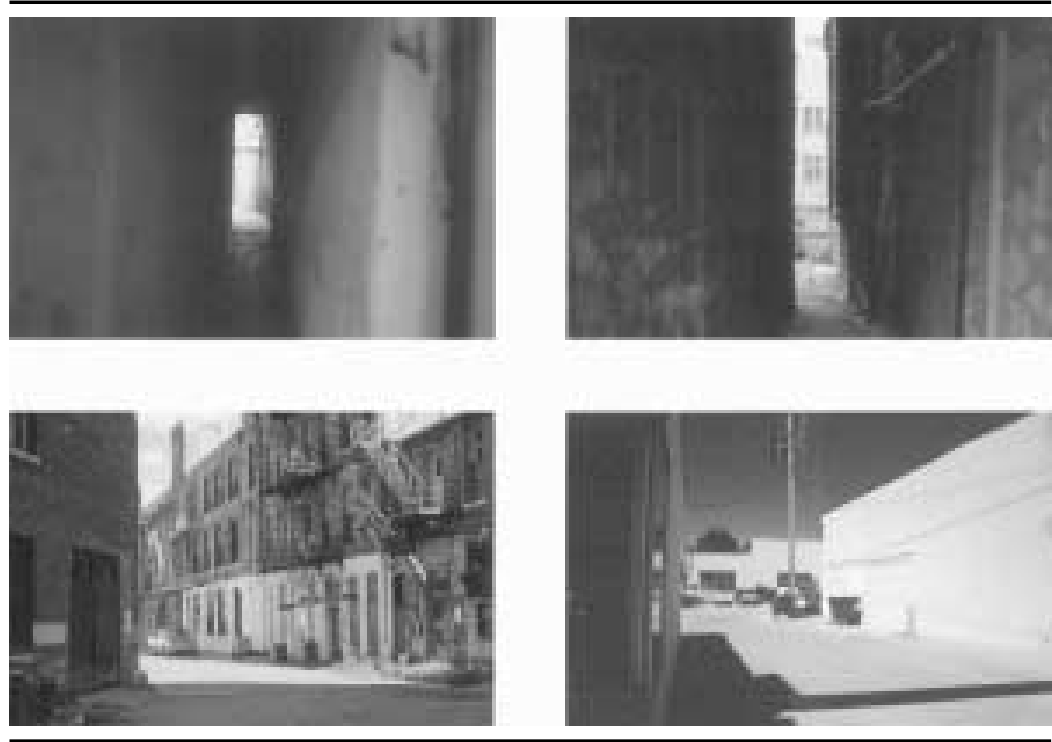

Figure 3: Alleys Low (Top Row) and High (Bottom Row) in Width

Mean Ratings for Curvature (C), Length (L), and Width (W): $C=2.58, L=3.00, W=1.42$ (Top Left) $\mathrm{C}=2.65, \mathrm{~L}=2.75, \mathrm{~W}=1.45$ (Top Right); $\mathrm{C}=3.68, \mathrm{~L}=3.41, \mathrm{~W}=4.24$ (Bottom Left); $\mathrm{C}=2.94, \mathrm{~L}=3.03$, $\mathrm{W}=4.21$ (Bottom Right).

variable, every setting had a setting score. Internal-consistency reliability coefficients (Cronbach's alpha), based on settings as cases and participants as items, ranged from .91 for mystery to .99 for preference.

Table 1 contains correlations among the nine rated variables of this study based on all 60 settings. Several points can be made. First, the correlation of .97 between preference and preference (safety guaranteed) suggests that both variables are measuring the same construct. Given that most past research has used the simple preference rating, preference (safety guaranteed) was not used in subsequent analyses. Second, the correlations among the six predictor variables are generally quite modest, suggesting no serious redundancy among the predictors. In particular, it would appear that our attempt to disentangle perceived curvature and length by means of judicious selection of settings was fairly successful. Although several of the correlations among the predictor variables are significant at $p<.05$, given that there are 15 such correlations, setting alpha to $.05 / 15=.003$ might be more appropriate. With that criterion, only one of the correlations, $r=-.69$ between mystery and width, is significant. Third, the pattern of prediction for preference and danger is different. With alpha at $.05 / 6=.008$ because there are six predictors, setting care 
TABLE 1

Correlations Among Rated Variables ( $N=60$ settings)

\begin{tabular}{|c|c|c|c|c|c|c|c|c|c|}
\hline Variables & 1 & 2 & 3 & 4 & 5 & 6 & 7 & 8 & 9 \\
\hline 1. Preference & - & $.97^{\star \star}$ & $-.75^{\star \star}$ & $.70^{* *}$ & .12 & -.24 & -.11 & .26 & .13 \\
\hline 2. Preference (safety & & & & & & & & & \\
\hline guaranteed) & & - & $-.74^{\star *}$ & $.68^{* *}$ & .14 & -.21 & -.10 & .24 & .08 \\
\hline 3. Danger & & & - & $-.73^{\star *}$ & $.47^{\star *}$ & $.48^{\star *}$ & -.02 & -.13 & $-.48^{\star \star}$ \\
\hline 4. Setting care & & & & - & $-.26^{\star}$ & .02 & -.01 & .08 & $.26^{*}$ \\
\hline 5. Mystery & & & & & - & $.32^{*}$ & -.08 & .05 & $-.69^{\star *}$ \\
\hline 6. Shadow & & & & & & - & $-.37^{* *}$ & ${ }^{*} .06$ & $-.37^{\star *}$ \\
\hline 7. Curvature & & & & & & & - & $-.36^{\star \star}$ & .18 \\
\hline 8. Length & & & & & & & & - & $.27^{*}$ \\
\hline 9. Width & & & & & & & & & - \\
\hline
\end{tabular}

is the only significant predictor of preference, a positive relation. For danger, setting care and width are negative predictors, whereas mystery and shadow are positive predictors. Fourth, the three predictors that are the focus of this study (curvature, length, and width) are relatively ineffective in accounting for either preference or danger. This cannot be a matter of limited range because the setting scores for each of these variables spans a range of from less than 1.5 to greater than 4.2 on the 5-point scale. Fifth, mystery is positively correlated with danger but uncorrelated with preference, whereas the two target variables are negatively correlated with each other.

To zero in on the specific question raised in the introduction, whether curvature has any relation with danger when length is controlled, we computed the partial correlation between danger and curvature, with length partialed out. Given the modest first-order correlations among these variables, there was little reason to expect anything dramatic, and indeed the partial correlation was only -.07 .

The counterintuitive negative relation between curvature and danger for alleys showed up not only in the simple correlations of the Herzog and Miller (1998) study but also in regression analyses involving all of their predictors. Consequently, we performed regression analyses for both preference and danger as target variables. For both analyses, the six rated predictors were the predictor variables. The results are presented in Table 2. With alpha set at .05/ $6=.008$, two of the predictors showed opposite patterns for predicting the two targets. Setting care was a positive predictor of preference and a negative predictor of danger, whereas shadow had the reverse pattern. Mystery did an about-face compared to what is seen in the simple correlations of Table 1. Here, mystery was a positive predictor of preference but did not predict 
TABLE 2

Regression of Preference and Danger on Six Rated Predictors ( $N=60$ Settings)

\begin{tabular}{lrrrrrrr}
\hline & \multicolumn{3}{c}{ Preference } & & \multicolumn{3}{c}{ Danger } \\
\cline { 2 - 4 } \cline { 6 - 8 } Predictor & $\mathrm{B}$ & Partial $\mathrm{r}$ & $\mathrm{p}$ & & $\mathrm{B}$ & Partial $\mathrm{r}$ & $\mathrm{p}$ \\
\hline Setting care & .58 & .87 & $<.001$ & & -.60 & -.85 & $<.001$ \\
Mystery & .62 & .65 & $<.001$ & & .16 & .19 & .158 \\
Shadow & -.34 & -.68 & $<.001$ & & .44 & .72 & $<.001$ \\
Curvature & -.15 & -.40 & .002 & & .13 & .30 & .027 \\
Length & .05 & .12 & .366 & & -.05 & -.10 & .476 \\
Width & .13 & .22 & .109 & & -.04 & -.06 & .663 \\
\hline
\end{tabular}

NOTE: $B$ is the raw score regression weight. For preference, $R^{2}=.81, p<.001$; for danger, $R^{2}=.83$, $p<.001$.

danger. Width and length were ineffective as predictors of either target, but curvature was a modest negative predictor of preference. If alpha is set at .05 , the only change in results is that curvature was also a modest positive predictor of danger. ${ }^{1}$

The collinearity diagnostics for the preceding regression analyses indicated possible problems with multicollinearity. According to Tabachnick and Fidell (1996), "criteria for multicollinearity are a conditioning index $>30$ and at least two variance proportions $>.50$ for a given root number" (p. 87). The collinearity diagnostics for the preceding analyses met this criterion, and the two offending predictors were mystery and width, just as Table 1 might suggest. The cure is to drop one of the predictors or to combine them. We were far more interested in the informational predictor mystery than in the relatively straightforward perceptual predictor width. Consequently, we repeated the regression analyses without width as a predictor. The results are presented in Table 3. The only change from the previous analyses was that mystery was now a significant positive predictor of danger with alpha at .05 but was not quite significant with alpha at $.05 / 5=.01(p=.018)$.

\section{DISCUSSION}

The three predictors that were the primary focus of this study had at best only modest relations with the target variables. In the simple correlations, alley width was negatively related to perceived danger, suggesting that narrow alleys are seen as more dangerous, an intuitively sensible result. In contrast to the findings in the Herzog and Miller (1998) study, alley curvature had 
TABLE 3

Regression of Preference and Danger on Five Rated Predictors ( $N=60$ Settings)

\begin{tabular}{lrrrrrrrr}
\hline & \multicolumn{3}{c}{ Preference } & & \multicolumn{3}{c}{ Danger } \\
\cline { 2 - 4 } \cline { 6 - 8 } Predictor & $\mathrm{B}$ & Partial $\mathrm{r}$ & $\mathrm{p}$ & & $\mathrm{B}$ & Partial $\mathrm{r}$ & $\mathrm{p}$ \\
\hline Setting care & .59 & .87 & $<.001$ & & -.60 & -.85 & $<.001$ \\
Mystery & .51 & .69 & $<.001$ & & .20 & .31 & .018 \\
Shadow & -.35 & -.69 & $<.001$ & & .44 & .73 & $<.001$ \\
Curvature & -.13 & -.35 & .008 & & .12 & .30 & .027 \\
Length & .10 & .26 & .051 & & -.06 & -.15 & .275 \\
\hline
\end{tabular}

NOTE: $B$ is the raw score regression weight. For preference, $R^{2}=.80, p<.001$; for danger, $R^{2}=.83$, $p<.001$.

no relation to either target variable in the simple correlations, and its inability to predict danger persisted after controlling statistically for alley length. However, in regression analyses controlling for all other predictors, curvature had a modest negative partial relation with preference and a modest positive partial relation with danger, the latter relation significant only with the relatively liberal criterion of alpha equal to .05 . These results also contrast with Herzog and Miller's, where curvature did not directly predict preference and was a negative partial predictor of danger for alleys. Where conflicting results regarding alleys are concerned, the present study would seem to carry more weight because of its larger and broader sampling of alleys. A positive relation between curvature and danger for alleys would seem intuitively to make more sense and was in fact the result originally predicted by Herzog and Miller. The rationale is that a sharply curving alley provides a hiding place for predators in a setting with a generically dangerous reputation. Thus, pending further evidence, a sensible tentative conclusion is that curvature is at best a weak predictor of either preference or danger for alleys.

The remaining three predictors generally had more substantial relations with the target variables in both the simple correlations and the regression analyses. Setting care and shadow predicted preference and danger in opposite ways. Setting care was a positive predictor of preference, whereas shadow was a negative predictor. The reverse pattern held for predicting danger. These relations make sense in that setting care generally implies an orderly setting and regular surveillance on the part of caretakers. This is the kind of symbolic message that should enhance positive affective reactions. The opposite message is sent by a setting lacking in care, and, indeed, when measured directly, setting care has been shown to be a negative predictor of perceived danger (e.g., Herzog \& Chernick, 2000). Shadow may have both direct and indirect effects. Theoretically, shadow should be a contributor to 
mystery, thereby indirectly influencing affective reactions. Table 1 shows a modest positive correlation between the two variables. In a previous study (Herzog \& Smith, 1988), shadow showed no ability to predict preference independently of mystery. In this study, however, shadow did predict independently, as shown in the regression analyses, suggesting that it can have direct effects on affective reactions. The nature of those direct effects seems to be that shadow depresses preference and enhances danger reactions. This makes good sense for urban alleys but may not hold for other setting categories, suggesting that any effect of shadow may be context dependent.

The fact that setting care and shadow predicted preference and danger in opposite ways does not mean that preference and danger should be thought of as polar opposites. Their intercorrelation, though strongly negative (-.75), implies that only a little more than half of their variance is shared. Moreover, one predictor, mystery, did not relate to the two target variables in opposite ways. The pattern of differences in effective predictors for positive and negative affective reactions has been found previously (Herzog \& Chernick, 2000) and suggests caution in assuming that one reaction is simply the inverse of the other. As Herzog and Miller (1998) point out, echoing Hebb (1972), danger and fear can be attractive in certain contexts.

The present results were generally compatible with the paradoxical role for mystery documented by Herzog and Miller (1998), although full replication was elusive. Herzog and Miller's finding was that mystery was a positive predictor of both preference and danger, even though the latter two variables were negatively related, an unbalanced pattern of relations. That finding showed up clearly and significantly only in their regression analyses that included all predictor variables. In the present study, both the simple and partial correlations for mystery as a predictor of either target variable were always positive. However, for the simple correlations, only the one for danger was significant (Table 1), whereas for the partial correlations, only the one for preference was unambiguously significant (Tables 2 and 3). In the regression analysis without multicollinearity among the predictors (Table 3 ), the expected positive partial relation between mystery and danger fell just short of significance with the conservative criterion of alpha $=.01$. Thus, the present results tend toward the same pattern as Herzog and Miller's but are not as strong. It is well to remember that the Herzog and Miller study included both alleys and field-forest settings, whereas the present study included a much broader sample of alleys only. Herzog and Miller emphasize that the paradoxical role for mystery is likely to be context dependent. The present results are compatible with that caveat.

An interesting methodological implication of the present study is that preference defined without reference to safety (the typical approach) and 
preference defined so that safety is explicitly guaranteed are virtually redundant $(r=.97)$. This would seem to imply that raters of preference as typically defined implicitly assume that safety is not an issue. More circuitous explanations are possible, but this one seems the most straightforward. Researchers using the typical definition of preference have generally assumed that their raters were making the implicit assumption noted above. Now there is empirical evidence to support their assumption.

The usual caveats must be offered. First, our population was college students, and there is reason to suppose that the affective reactions of college students to environmental settings do not necessarily generalize to other age groups (Balling \& Falk, 1982; Herzog, Herbert, Kaplan, \& Crooks, 2000; Zube, Pitt, \& Evans, 1983). Second, we used color slides to present the settings. Although legitimate concerns about the generality of results from this medium of presentation have been raised (e.g., Heft \& Nasar, 2000; Hetherington, Daniel, \& Brown, 1993; Scott \& Canter, 1997), the validity of the medium for aggregate results and static visual attributes of environments is strongly supported (e.g., Hershberger \& Cass, 1973; Hull \& Stewart, 1992; Sommer, Summit, \& Clements, 1993; Stamps, 1990; Trent, Neumann, \& Kvashny, 1987; Zube, Simcox, \& Law, 1987). Third, our predictors all involved perceived features, although in some cases (shadow, curvature, length, and width), more objective measures could have been obtained. Although we appreciate the views of those who favor objectively measured predictors, we favor perceived measures as predictors because people react to what they perceive. In addition, such measures have a long tradition in landscape assessment research. Finally, we find it satisfying that the more deeply theoretical and psychological predictors (mystery, setting care, shadow) were generally more effective than those aimed at simpler and more directly perceptual features (curvature, length, width), despite that fact that our primary purpose was to sort out the effects of the latter group.

\section{NOTE}

1. To determine whether setting categories might shed some light on the prediction of the target variables, we factor analyzed the raw preference ratings (principal-axis factoring, varimax rotation). Two factors or preference categories emerged, containing 18 and 19 settings, respectively. The categories differed significantly on all but two of the predictors, with the first category rated higher in mystery and shadow and lower in setting care and width. Given the strong relations between setting categories and the predictors, it seemed unlikely that adding setting category to the regression analyses would yield much insight, but we tried anyway. For both target variables, we used step-down regression analysis (Aiken \& West, 1991), starting with a model 
that included all six predictors, setting category, and the interaction of each predictor and setting category. We then proceeded to eliminate nonsignificant interactions followed by nonsignificant simple effects, using the guidelines suggested by Aiken and West. For both target variables, this resulted in the elimination of all of the interactions and then of the simple effect of setting category, leaving us with a model consisting of only the six rated predictors. The results, with the reduced set of 37 settings, were almost identical to those in Table 2, the sole difference being that width was a significant positive partial predictor of preference (but not danger) in the analysis of category settings only.

\section{REFERENCES}

Aiken, L. S., \& West, S. G. (1991). Multiple regression: Testing and interpreting interactions. Newbury Park, CA: Sage.

Balling, J. D., \& Falk, J. H. (1982). Development of visual preference for natural environments. Environment \& Behavior, 14, 5-28.

Brantingham, P. L., \& Brantingham, P. J. (1993). Nodes, paths, and edges: Considerations on the complexity of crime and the physical environment. Journal of Environmental Psychology, $13,3-28$.

Fisher, B. S., \& Nasar, J. L. (1992). Fear of crime in relation to three exterior site features: Prospect, refuge, and escape. Environment \& Behavior, 24, 35-65.

Hebb, D. O. (1972). Textbook of psychology (3rd ed.). Philadelphia: W. B. Saunders.

Heft, H., \& Nasar, J. L. (2000). Evaluating environmental scenes using dynamic versus static displays. Environment \& Behavior, 32, 301-322.

Hershberger, R. G., \& Cass, R. C. (1973). The adequacy of various media as representations of the designed environment. Man-Environment Systems, 3, 371-372.

Herzog, T. R., \& Chernick, K. K. (2000). Tranquility and danger in urban and natural environments. Journal of Environmental Psychology, 20, 29-39.

Herzog, T. R., Herbert, E. J., Kaplan, R., \& Crooks, C. L. (2000). Cultural and developmental comparisons of landscape perceptions and preferences. Environment \& Behavior, 32, 323346.

Herzog, T. R., \& Miller, E. J. (1998). The role of mystery in perceived danger and environmental preference. Environment \& Behavior, 30, 429-449.

Herzog, T. R., \& Smith, G. A. (1988). Danger, mystery, and environmental preference. Environment \& Behavior, 20, 320-344.

Hetherington, J., Daniel, T. C., \& Brown, T. C. (1993). Is motion more important than it sounds? The medium of presentation in environment perception research. Journal of Environmental Psychology, 13, 283-291.

Hull, R. B., IV, \& Stewart, W. P. (1992). Validity of photo-based scenic beauty judgments. Journal of Environmental Psychology, 12, 101-114.

Kuo, F. E. (2001). Coping with poverty: Impact of environment and attention in the inner city. Environment \& Behavior, 31, 5-34.

Kuo, F. E., Bacaicoa, M., \& Sullivan, W. C. (1998). Transforming inner-city landscapes: Trees, sense of safety, and preference. Environment \& Behavior, 30, 28-59.

Loewen, L. J., Steel, G. D., \& Suedfeld, P. (1993). Perceived safety from crime in the urban environment. Journal of Environmental Psychology, 13, 323-331. 
Nasar, J. L., \& Fisher, B. (1993). "Hot spots" of fear and crime: A multi-method investigation. Journal of Environmental Psychology, 13, 187-206.

Nasar, J. L., \& Jones, K. M. (1997). Landscapes of fear and stress. Environment \& Behavior, 29, 291-323.

Perkins, D. D., Meeks, J. W., \& Taylor, R. B. (1992). The physical environment of street blocks and resident perceptions of crime and disorder: Implications for theory and measurement. Journal of Environmental Psychology, 12, 21-34.

Perkins, D. D., Wandersman, A., Rich, R. C., \& Taylor, R. B. (1993). The physical environment of street crime: Defensible space, territoriality and incivilities. Journal of Environmental Psychology, 13, 29-49.

Schroeder, H. W., \& Anderson, L. M. (1984). Perception of personal safety in urban recreation sites. Journal of Leisure Research, 16, 178-194.

Scott, M. J., \& Canter, D. V. (1997). Picture or place? A multiple sorting study of landscape. Journal of Environmental Psychology, 17, 263-281.

Sommer, R., Summit, J., \& Clements, A. (1993). Slide ratings of street-tree attributes: Some methodological issues and answers. Landscape Journal, 12, 17-22.

Stamps, A. E., III. (1990). Use of photographs to simulate environments: A meta-analysis. Perceptual and Motor Skills, 71, 907-913.

Tabachnick, B. G., \& Fidell, L. S. (1996). Using multivariate statistics (3rd ed.). New York: HarperCollins.

Taylor, R. B., Shumaker, S. A., \& Gottfredson, S. D. (1985). Neighborhood-level links between physical features and local sentiments: Deterioration, fear of crime and confidence. Journal of Architectural and Planning Research, 2, 261-275.

Trent, R. B., Neumann, E., \& Kvashny, A. (1987). Presentation mode and question format artifacts in visual assessment research. Landscape and Urban Planning, 14, 225-235.

Wells, N. M. (2000). At home with nature: Effects of "greenness" on children's cognitive functioning. Environment \& Behavior, 32, 775-795.

Wilson, J. Q. (1975). Thinking about crime. New York: Basic Books.

Wilson, J. Q., \& Knelling, G. (1982, March). Broken windows: The police and neighborhood safety. Atlantic Monthly, 29-38.

Zube, E. H., Pitt, D. G., \& Evans, G. W. (1983). A lifespan developmental study of landscape assessment. Journal of Environmental Psychology, 3, 115-128.

Zube, E. H., Simcox, D. E., \& Law, C. S. (1987). Perceptual landscape simulations: History and prospect. Landscape Journal, 6, 62-80. 